\title{
Эффрективное участие меньшинств как балансирующий фактор: роль Верховного комиссара ОБСЕ по делам национальных меньшинств
}

\author{
Гаэтано Пентассулья*
}

\section{Аннотациия}

В чем заключается роль Верховного комиссара ОБСЕ по делам национальных меньшинств в контексте участия национальных меньшинств в общественно-политической жизни их стран? На основе Лундских рекомендаций и других международных документов в данной статье предпринята попытка ответить на этот вопрос, анализируя отдельные аспекты участия меньшинств, включая политические партии, особые меры, консультативные органы и самоуправление на фоне более широких и часто упоминаемых понятий интеграции и сепарации. В ней выделены направления, в которых установленные Лундскими рекомендациями Верховного комиссара стандарты нуждаются в дальнейшем развитии и уточнении. Статья завершается рекомендациями относительно будущей деятельности Верховного комиссара ОБСЕ по делам национальных меньшинств.

\section{Ключевые слова}

политическое участие, интеграция, сепарация, ВКНМ, международное право

Для цитирования этой публикации: Пентассулья Г. Эффективное участие меньшинств как балансирующий фактор: роль Верховного комиссара ОБСЕ по делам национальных меньшинств // ОБСЕ Insights 6/2021 - Баден-Баден: Номос, 2022. URL: https://doi.org/ $10.5771 / 9783748911463-06$

\section{Введение: подход ВКНМ к интеграции и сепарации с целью предотвращения конфликтов}

Пост Верховного комиссара ОБСЕ по делам национальных меньшинств (ВКНМ) был учрежден в 1992 г. в качестве инструмента предупреждения конфликтов, задача которого заключается в обеспечении «раннего предупреждения» и «срочных действий» в крайне чувствительной сфере, относящейся к вопросам меньшинств ${ }^{1}$.

* Гаэтано Пентассулья, профессор международного права, юридический факультет Ливерпульского университета имени Джона Мурса, почетный старший научный сотрудник Ливерпульского университета, g.pentassuglia@ljmu.ac.uk 
ВКНМ часто противопоставлял стратегии «сепарации» политику «интеграции» как жизненно важного элемента любой формы долговременной защиты меньшинств в государстве ${ }^{2}$.

Противопоставление интеграции и сепарации свойственно и другим международным структурам, занимающимся деятельностью, связанной с межгрупповыми отношениями, особенно тем, которые стремятся учесть особые интересы и стремления соответствующих групп (например, недискриминация и независимость). Однако подход ВКНМ к интеграции и сепарации отличается от подходов других структур. Интеграция понимается им как необходимое условие поддержания единства общества в условиях многообразия, в то время как сепарация рассматривается чрез призму признания конкретных прав той или иной группы, не предполагающего формирования у ее членов более широкого чувства принадлежности к обществу в целом и признания прав других групп. Показательный пример - защита прав в области использования языка. Тезис о том, что право использовать и изучать родной язык в образовательных учреждениях и (или) использовать его в органах государственного (местного) управления, чего, собственно, и добиваются национальные меньшинства, не должно рассматриваться в отрыве от необходимости преподавания и изучения официального государственного языка для аналогичных целей, стал мантрой $\mathrm{BKHM}^{3}$. Политика, в частности, стран Балтии, Грузии, Казахстана и Кыргызстана в том, что касается решения вопросов меньшинств, использования их языков и развития межэтнического диалога, формировавшаяся при содействии со стороны ВКНМ, соответствует этому подходу. Она также соответствует международным стандартам ${ }^{4}$.

Таким образом «интеграция в условиях многообразия», если использовать терминологию ВКНМ, предполагает как легитимность, так и определенные границы защиты национальных меньшинств. Взаимосвязь интеграции и участия в общественно-политической жизни является лучшей иллюстрацией этого баланса. Право на участие в принятии решений по важным для той или иной группы вопросам, а также в общественной жизни в целом - неотъемлемый элемент всех международных норм, как универсальных, так и региональных, применимых к различным группам населения. Права на участие могут иметь политические, социально-экономические и культурные последствия, а их интеграционная суть заключается в предоставлении представителям соответствующей группы «эффективного» права голоса при принятии решений или, по крайней мере, в обеспечении их участия в процессах формирования государственной политики в ряде областей.

Лундские рекомендации об эффективном участии национальных меньшинств в общественно-политической жизни (далее - Лундские рекомендации) ${ }^{5}$, обнародованные ВКНМ в 1999 г., сосредоточены на политических аспектах участия меньшинств, подтверждая необходимость демократической и плюралистической структуры, позволяющей интегрировать многообразие групп в общество и противодействовать представлениям о национальной идентичности как о чем-тот монолитном 
или основанным на тезисе об исключительности какой-то группы населения. В рекомендациях также определены конкретные параметры такого участия в соответствии со стандартами прав человека.

Используя в качестве основы для анализа Лундские рекомендации и другие международные документы ${ }^{6}$, в данной работе рассматриваются отдельные направления обеспечения политического участия меньшинств, связанные с деятельностью ВКНМ, такие как политические партии, особые меры, консультативные органы и самоуправление на фоне более широких понятий интеграции и сепарации. В следующем разделе выделены те направления, на которых формирующиеся под эгидой ВКНМ на основе Лундских рекомендаций стандарты нуждаются в совершенствовании или уточнении. К ним относятся, в частности, роль общенациональных партий, уточнение некоторых особых мер, применяемых в рамках избирательных процессах, тип и глубина плюрализма, обеспечиваемого консультативными органами, а также взаимосвязь между самоуправлением, интеграцией и десекьюритизацией, особенно в трансграничных регионах. В заключительном разделе предложен краткий набор рекомендаций с акцентом на будущую деятельность ВКНМ.

\section{Направления деятельности ВКНМ в свете Лундских рекомендаций и других международных стандартов}

\section{Политические партии}

В то время как в ряде государств-участников ОБСЕ (в частности, в Болгарии, России и Турции) прямо запрещено формирование партий по этническому признаку или партий, представляющий национальные меньшинства, ВКНМ проявляет гибкость, признавая, что и общенациональные партии, и партии и движения национальных и региональных меньшинств являются легитимными формами участия последних в общественно-политической жизни и, таким образом, легитимными инструментами их интеграции в общенациональное публичное пространство, политического представительства и участия в принятии решений.

Лундские рекомендации открыто одобряют этот дуализм. Явно или косвенно он также признается в тематическом комментарии Консультативного комитета Рамочной конвенции Совета Европы о защите национальных меньшинств ${ }^{7}$ и Европейским судом по правам человека. Однако при этом важно понимать, что стратегии интеграции и сепарации применительно к сфере партийного строительства будут иметь различные правовые и политические последствия.

В этой связи следует отметить четыре аспекта. Во-первых, там, где они существуют, партии меньшинств не должны рассматриваться как угроза для национальной безопасности, если только их деятельность не представляет убедительные доказательства обратного (здесь уместно напомнить о ряде дел против Турции, ставших 
предметом слушаний в Европейском суде по правам человека). Это также означает, что законодательные запреты этнических партии и политических движений представляют собой нарушение свободы ассоциаций в соответствии с международным правом в области прав человека, если только такие запреты не направлены против групп, в отношении которых существует доказательная база, свидетельствующая об их насильственной и антидемократической деятельности.

Во-вторых, хотя участие меньшинств в общенациональных партиях в целом приветствуется и даже поощряется, четких критериев оценки эффективности такого участия нет. Несмотря на общие права, такие как право на участие в ведении государственных дел согласно статье 25 Международного пакта о гражданских и политических правах ${ }^{8}$ - включая активное и пассивное избирательное право, а также более широкое определение внутреннего самоопределения - партии меньшинств могут оказаться, как сказано в Лундских рекомендациях, «единственной надеждой на эффективное представительство их специфических интересов, и, таким образом, на их реальное участие в жизни общества» 9 . Консультативный комитет Рамочной конвенции признает, что включения представителей меньшинств в общенациональные партии может быть недостаточно для эффективного представительства их интересов $^{10}$, и по этой причине у меньшинств должна быть возможность как для участия в общенациональных, так и для создания собственных партий. Однако международные стандарты в отношении меньшинств, включая Лундские рекомендации, не содержат четкие критерии представительства интересов меньшинств в общенациональных партиях, соответствие которым могло бы считаться достаточным для

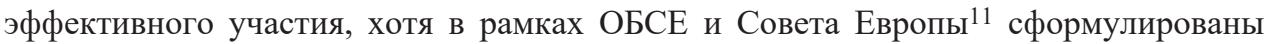
более конкретные положения, касающиеся избирательного процесса в целом, затрагивающего интересы национальных меньшинств.

В-третьих, общенациональным партиям самим необходимо найти баланс между интересами «большинства» и «меньшинства». Повестка дня таких партий обычно формируется на основе вопросов, которые, хотя и являются потенциально общими, тем не менее в первую очередь отражают приоритеты большинства населения. Показательно, что в тематическом комментарии Консультативного комитета Рамочной конвенции Совета Европы порядок отбора кандидатов рассматривается в качестве ключевого вопроса, определяющего, в какой мере программа общенациональной партии будет отражать интересы меньшинства ${ }^{12}$. В этом вызове нашла отражение более широкая проблема интеграции меньшинств в обществе.

В-четвертых, если в традиционных либеральных демократиях широкое включение в политику волнующих меньшинства вопросов может быть достигнуто через общенациональные партии, то в некоторых регионах ОБСЕ, в частности, в ряде государств Центральной Азии, там, где этническая принадлежность часто представляет собой укоренившийся маркер идентичности в партийной политике и общественной жизни в целом, такое решение более проблематично. 


\section{Особые меры}

Ряд конкретных мер, разработанных прямо или косвенно для того, чтобы содействовать участию национальных меньшинств в политическом процессе, обычно называют «особыми механизмами» или, чаще, «особыми мерами». Они варьируются от формальных и неформальных мер, направленных на обеспечение более инклюзивного избирательного процесса - например, определение границ избирательных округов, доступность относящихся к выборам материалов как на языке большинства населения, так и на языках меньшинств, возможность использовать языки меньшинств в ходе избирательной кампании и даже общие положения законодательства о выборах, влияющие на участие в голосовании (язык, гражданство и так далее) - до мер, адресованных конкретной группе населения. Последние могут включать предоставление второго голоса или резервирование мест в выборных органах (парламенте, региональных собраниях и так далее). ВКНМ и другие институты обсуждали и в той или иной степени поддержали применение таких мер в ряде стран $^{13}$.

Первая группа мер служит для обеспечения, в основном косвенно, минимальных условий, необходимых для того, чтобы меньшинства могли воспользоваться преимуществами участия в общенациональных политических процессах, которые в противном случае принесли бы пользу только большинству населения. К таким мерам относятся, к примеру, снижение порога для представительства партий в выборных органах или распространение материалов общенациональной избирательной кампании в регионах проживания меньшинства на двух языках (см., например, материалы дела о про-курдских партиях в Турции). То же самое касается обеспечения более широкого представительства меньшинств в судебной системе и на государственной службе $\mathrm{e}^{14}$. Здесь интеграция, по сути, направлена на то, чтобы в составе институтов государственной власти справедливо отражалось многообразие общества.

Вторая группа мер также преследует эти общие цели, но выделяет те области, в которых наделение меньшинств особыми правами считается необходимым для обеспечения для них возможности отстаивать свои особые интересы. Некоторые из таких мер оказались проблематичными. Так, предоставление традиционным меньшинствам Словении второго голоса, позволяющего им голосовать как за общие партийные списки, так и отдельно за собственных представителей меньшинств на национальном или местном уровне, вызвало вопросы относительно совместимости такой системы с принципом равенства избирательных прав. В 1998 году Конституционный суд Словении отклонил жалобы на неконституционность данного порядка голосования, определив, что он призван исправить существенное неравенство между этническими словенцами и соответствующими группами меньшинств. В то время как ВКНМ с пониманием отнесся к этой практике, по крайней мере исходя из

интересов предотвращения конфликтов ${ }^{15}$, Венецианская комиссия Совета Европы 
узко трактовала практику предоставления права второго голоса как исключительно временную меру, применимую в условиях отсутствия более приемлемых альтернатив. В Лундских рекомендациях, в свою очередь, перечисляется ряд особых мер, но не уточняются условия и границы их применения.

В этой связи следует напомнить, что в контексте Конвенции ООН о ликвидации всех форм расовой дискриминации проводится четкое различие не только между позитивными обязательствами, вытекающими из ее статей (и, по аналогии, любыми стандартами в области прав человека и меньшинств), и «особыми мерами» как временной политикой позитивных действий, но и между последними и постоянными правами, принадлежащими меньшинствам и коренным народам: «Особые меры не следует путать с конкретными правами, принадлежащими определенным категориям лиц или общине... Такие права относятся к числу постоянных прав, признанных в качестве таковых в договорах по правам человека, в том числе документах, принятых в контексте деятельности Организации Объединенных Наций и ее специализированных учреждений. Государствам-участникам следует четко соблюдать различие между особыми мерами и постоянными правами человека в своих законах и на практике» ${ }^{16}$.

Если особая мера направлена на устранение исторически сложившегося неравенства и несправедливости в отношении группы меньшинства, следует предположить, что она не обязательно будет временной или переходной по своей природе, хотя с течением времени будет подлежать рассмотрению на предмет пропорциональности и возможной корректировки. Возможны и разумные альтернативы таким мерам как, к примеру, право второго голоса (оно применяется только в Словении и только в отношении определенных групп). Однако в целом амбициозные (позитивные) меры, такие как резервирование мест в выборных органах для представителей меньшинств и конкретные исключения из избирательных порогов, должны рассматриваться как prima facie защита прав меньшинств, отмена которой может отрицательно повлиять на участие меньшинств в общественно-политической жизни, нанести ущерб межобщинному доверию и социальной сплоченности ${ }^{17}$. В отсутствие очевидно лучшей политики, пользующейся широкой поддержкой группой меньшинства, акцент должен быть сделан на доработку и совершенствование соответствующих особых мер вместо того, чтобы рассматривать их как преходящие.

Примером здесь могут служить системы голосования национальных меньшинств, принятые в таких государствах-участниках ОБСЕ, как Венгрия и Казахстан. Несмотря на сложность этих систем, основанных главным образом на резервировании мест для представителей меньшинств, Бюро ОБСЕ по демократическим институтам и правам человека (БДИПЧ) обращает внимание на проблемы (потенциально устранимые), возникающие, в частности, в процессе выдвижения кандидатов по спискам меньшинств, в связи с уровнем выборов, в которых допускается участие представители меньшинств, и отсутствием системы регистрации избирателей, принадлежащих к меньшинствам. Но при этом БДИПЧ не ставит под вопрос 
общую легитимность и долговечность этих систем как механизмов защиты прав меньшинств ${ }^{18}$.

\section{Консультативные органы}

Учреждение консультативных органов является типичным примером минимального стандарта политики по интеграции меньшинств, призванного обеспечить их участие в общественно-политической жизни. Необходимые улучшения в этой сфере тщательно документированы и остаются важной частью оказываемых ВКНМ добрых услуг. Они включают вопросы, связанные с правовым статусом, полномочиями по принятию решений, частотой проведения консультаций и финансовыми ресурсами, которыми располагают такие органы.

В последнее время беспокойство вызывает плюрализм, который в контексте деятельности консультативных органов проявляется в двух формах. Первая - это плюрализм, существующий внутри конкретной группы, который необходимо учитывать для адекватного репрезентативного выражения разнообразных взглядов ее членов. Важность вопроса о репрезентативности и более широкой легитимности признана в ряде документов, в частности, в тематических комментариях к Рамочной конвенции Совета Европы и научных оценках, а в Лундских рекомендациях трезво отмечается, что «членский состав этих органов должен отвечать их назначению и способствовать более эффективному выражению и обеспечению интересов меньшинств» ${ }^{19}$. ВКНМ справедливо сосредоточил внимание на содействии внутригрупповому обсуждению соответствующих вопросов, обращая внимание, в частности, на то, в какой мере гендер может являться препятствием для участия в обсуждении (как это проявилось в недавних дискуссиях вокруг участия женщин из числа меньшинств в Северной Македонии). Международное право признает права на участие меньшинств как во внешней, так $u$ во внутренней сфере, что означает, что государство, признавая автономную ассоциативную жизнь сообщества, обязано как минимум проявлять должную заботу о том, чтобы обеспечить благоприятные условия для инклюзивной внутригрупповой дискуссии и, следовательно, для эффективного участия всех в соответствии с основными стандартами прав человека.

Внутренний плюрализм не обязательно ведет к тому, что позиция и требования группы распадутся на несогласованный набор чисто индивидуальных предпочтений и забот. В идеале плюрализм предполагает включение различных представленных в сообществе взглядов в общую позицию, которая может считаться общегрупповой, если она сформировалась с соблюдением правил подотчетности и демократических стандартов. Если же формирование общей позиции невозможно из-за внутренних разногласий (как это имело место в ряде европейских общин рома), основные группы сообщества должны получить право голоса и быть представлены в консультативных механизмах, как это сделал Европейский суд по правам человека в 
контексте избирательных процессов и прав голоса, касающихся внутриобщинных вопросов $^{20}$. Более широкая судебная и квазисудебная практика в области прав человека в целом признает широкие полномочия представителей групп в процессе выдвижения требований или определенный уровень защищенного плюрализма различных организаций, существующих в рамках группы, особенно в тех случаях, когда их представители назначаются государством, а не общиной ${ }^{21}$.

Последний пункт связан со второй формой плюрализма, относящейся к рассматриваемому нами контексту: то многообразие, которое проявляется в процессе участия различных групп или представителей групп в содержательном обсуждении представляющих для них интерес вопросов. Здесь речь идет о еще большем разбросе позиций, представленных всем спектром существующих в стране групп меньшинств, а не о внутригрупповом плюрализме. Как отмечает А. Петренко Томсен, готовность (и способность) группы участвовать в эффективных консультациях не менее важна, чем набор возможностей и средств участия, предусмотренных политическими и конституционными рамками государства 22 . Здесь стоит отметить, что в отличие от активного внутригосударственного и международного сетевого взаимодействия и лоббирования интересов коренных народов самостоятельная мобилизация национальных меньшинств носит более ограниченный характер. Лундские рекомендации не содержат конкретных положений на этот счет, однако в других международных документах сформулированы минимальные требования для обеспечения эффективного участия репрезентативного спектра организаций меньшинств в процессе консультаций. Государство должно не только позволять широкому спектру организаций меньшинств принимать участие в работе консультативных органов (наделенных юридическими полномочиями для того, чтобы такое участие имело смысл), но и активно поощрять и поддерживать - посредством обучения, кампаний по повышению осведомленности о правах и финансовых стимулов - участие в работе консультативных органов небольших организаций меньшинств, которые избегают интеграции в более широкие зонтичные структуры, представляющие основные группы в стране.

С точки зрения деятельности по предотвращению конфликтов состав и порядок функционирования консультативных органов, созданных в соответствии с национальным законодательством или на основе многосторонних или двусторонних соглашений (в основном это - двусторонние соглашения, касающиеся трансграничных регионов) требуют постоянного внимания со стороны ВКНМ, поскольку они относятся к основным показателям качества и глубины интеграционного подхода к решению вопросов меньшинств и укрепления доверия. В ряде случаев (например, в Казахстане и Узбекистане) такие механизмы еще отсутствуют. На данном направлении целесообразно осуществление более целенаправленной деятельности ВКНМ, особенно в том, что касается обеспечения плюрализма и соблюдения стандартов. Это особенно важно, учитывая скупые положения Лундских рекомендаций, более подробные формулировки тематического комментария к Рамочной конвенции Со- 
вета Европы и ожидание того, что организации меньшинств будут добросовестно взаимодействовать с государственными органами в рамках основанного на участии двустороннего процесса интеграции.

\section{Самоуправление}

Лундские рекомендации включают территориальную и нетерриториальную автономию в число механизмов реализации права на эффективное участие национальных меньшинств в общественной жизни ${ }^{23}$. Хотя признание таких форм самоуправления, по сути, отражает распространенную в Европе и за ее пределами национальную (конституционную) практику, в географическом регионе ОБСЕ после принятия Лундских рекомендаций в 1999 г. не появилось новых территориальных автономных образований. Более того, принятие рекомендаций и других международных стандартов не привело (и вряд ли приведет) к закреплению права на автономию в международном праве.

Тем не менее, было бы ошибкой отвергать Лундские рекомендации как бесполезные. В их пользу говорят несколько политических соображений. Во-первых, представляется, что любое достигнутое в результате переговоров урегулирование так называемых «замороженных» конфликтов на постсоветском пространстве, список которых недавно пополнился Крымом и юго-восточной Украиной, будет предусматривать механизмы самоуправления, если только заинтересованные стороны не сочтут приемлемыми иные решения. Проекты формирования «монолитных» наций (в Украине и других странах) так же не способствуют решению проблемы, как и завышенные требования меньшинств. Во-вторых, самоопределение в рамках существующего государства (внутреннее самоопределение), вариант, который убежденно проповедовал М. ван дер Стул, первый в истории ВКНМ, получает все более широкое признание в международном сообществе (не только в Западной Европе и Северной Америке) как часть международного права и позволяет в каждом случае разработать форму самоуправления, соответствующую конкретным обстоятельствам и стандартам уважения прав человека. Даже после принятия решения о предоставлении автономии (к примеру, о самоуправлении в Гагаузии в Молдове) на основе соответствующей интеграционной политики необходимо прилагать постоянные усилия, направленные на воспитание более широкого чувства национальной принадлежности, на что обращает внимание ВКНM $^{24}$. В-третьих, нетерриториальные решения, включенные в Лундские рекомендации, являются одним из механизмов интеграции в условиях многообразия (таких как политика многоязычного и качественного образования), способствующим трансформации требований о предоставлении автономии на основе гибкой комбинации политических и правовых мер. Наконец, жизнеспособность различных вариантов автономии по-прежнему проходит испытание в условиях как вооруженных конфликтов, так и влияния, 
оказываемого соседними странами, считающимися «исторической родиной» для меньшинств, проживающих в том или ином государстве.

Эти обстоятельства указывают на то, что изложенный в Лундских рекомендациях подход к самоуправлению следует интерпретировать в свете других рекомендаций ВКНМ и прежде всего - Люблянских рекомендаций 2012 г. по интеграции разнообразных обществ и Больцанских рекомендаций 2008 г. о национальных меньшинствах в межгосударственных отношениях ${ }^{25}$. Какими бы дифференцированными формами политического участия ни пользовались субгосударственные национальные группы в процессе внутреннего самоопределения в общенациональных рамках, они не должны рассматриваться как ступеньки на не знающем компромиссов пути к определенной группой конечной цели, будь то обретение независимости и суверенитета или реализация уникальной, не подлежащей обсуждению концепции самоуправления, в которой предпочтение отдается стратегии сепарации, а не интеграции (в смысле общегосударственной социальной сплоченности). Люблянские рекомендации напоминают нам: «для общества крайне важно найти надлежащий баланс между степенью разделения, необходимой для свободного выражения и развития разнообразия с одной стороны, и созданием и укреплением связей между разнообразными сообществами, составляющими все общество в целом, с другой стороны» $^{26}$.

Больцанские рекомендации подчеркивают территориальную целостность, добрососедские отношения, уважение прав человека, включая принцип недискриминации, и демократическое управление как ключевые основы трансграничной региональной политики с участием государств, представляющих собой историческую родину меньшинств, независимо от того, какие институциональные решения будут найдены для удовлетворения интересов соответствующих групп.

Вопрос о венгерском меньшинстве в Украине до и после Евромайдана 2014 г. иллюстрирует относительную значимость автономии с точки зрения защиты национальных меньшинств. С одной стороны, неблагоприятные границы избирательных округов, высокие пороги для представительства партий в выборных органах, произвольное включение отдельных лидеров меньшинств в избирательные списки основных национальных партий и отсутствие до недавнего времени официального консультативного органа для решения проблем национальных меньшинств препятствовали эффективному участию последних в политической жизни. С другой стороны - размывание прав на использование на местном уровне родного языка и на получение образования на нем после принятия в 2017 и 2019 гг. новых законов об образовании и государственном языке, ограниченный прогресс в территориальной и нетерриториальной децентрализации или его отсутствие, а также растущее влияние соседнего «родственного» государства еще больше усугубили и без того технически сложную и политически деликатную проблему ${ }^{27}$.

ВКНМ участвует в обсуждении большинства этих вопросов, особенно в контексте разработки законопроекта о меньшинствах, который должен заменить Закон о 
национальных меньшинствах 1992 г. ${ }^{28}$ Обсуждение предложений по реформированию местных органов власти в Украине в целом может открыть возможности для учета интересов меньшинств на основе сочетания расширенных прав на использование родного языка и получение образования на нем в районах традиционного проживания венгров (которые должны быть сбалансированы с преподаванием и изучением государственного языка) и формирования приемлемых институтов самоуправления.

Пример венгерского меньшинства в Украине наглядно иллюстрирует многогранность проблемы защиты прав меньшинств и неоднозначность подходов к автономии в реальном мире: помимо оформления «территориальных прав» как таковых самоуправление позволяет ставить и обсуждать различные вопросы, затрагивающие интересы группы, отдельных лиц и стабильности государства. В этом смысле Лундские рекомендации помогают понять проблемы той или иной страны и вместе с другими рекомендациями ВКНМ и международными стандартами предлагают демократическую основу для их решения в условиях, когда власти спекулируют на проблемах меньшинств в своих интересах. Однако влияние соседних государств, представляющих «историческую родину» меньшинств, усиливает настороженность властей в отношении требований о предоставлении автономии, поскольку они воспринимаются как угроза для единства общества. Перед ВКНМ стоит задача, содействуя десекьюритизации влияния соседних государств, найти баланс между потребностями общественной и институциональной интеграции и необходимостью удовлетворения законных требований самоуправления.

\section{Заключение и рекомендации}

Используя Лундские рекомендации и другие международные стандарты в качестве основы для анализа, в данном материале мы попытались выделить те формы политического участия меньшинств, в отношении которых существует понимание необходимости уравновесить интересы интеграции и сепарации. Не существует стандартного международно-правового определения «эффективности» вовлечения групп или каких-либо общепринятых параметров, характеризующих это понятия. Тем не менее продолжение деятельности ВКНМ в данной сфере представляется крайне желательным по крайней мере в интересах предотвращения потенциальных конфликтов. В этой связи ниже перечислены возможные направления будущей деятельности ВКНМ с акцентом на Лундские рекомендации.

1. Политические партии. Хотя ВКНМ исходит из того, что и общенациональные партии, и партии меньшинств представляют собой легитимные формы политического участия национальных меньшинств, Лундские рекомендации не содержат ясных положений относительно того, какие формы включения интересов 
меньшинств в повестку дня общенациональных партий соответствовали бы критериям эффективного участия меньшинств в общественно-политической жизни. В этой связи можно было бы подробнее проработать вопрос о практических формах участия меньшинств в деятельности общенациональных партий, включая гарантии, исключающие произвольную кооптацию отдельных лидеров меньшинств и размывание их коллективного политического участия.

2. Особые меры. ВКНМ следует оценивать вклад особых мер в интеграцию меньшинств в избирательный процесс со здоровой дозой политического реализма. В отсутствие явно более эффективной и пользующейся широкой поддержкой меньшинств политики основное внимание следует уделить доработке и совершенствованию мер, касающихся выдвижения кандидатов по спискам меньшинств, уровня выборов, в которых участвуют представители меньшинств и регистрации избирателей, принадлежащих к меньшинствам (в координации с БДИПЧ). Это - еще одна сфера, в которой Лундские рекомендации могут быть доработаны путем уточнения различий между комплексными формами защиты меньшинств и общими антидискриминационными мерами.

3. Консультативные органы. Хотя можно с уверенностью утверждать, что состав и функционирование консультативных органов, создаваемых в соответствии с национальным законодательством или на основе стандартов, установленных многосторонними и двусторонними соглашениями (в основном - двусторонними договорами в трансграничных регионах), являются центральным элементом любого заслуживающего доверия подхода государства к решению проблем меньшинств на основе «интеграции в условиях многообразия», положения Лундских рекомендаций на этот счет весьма скупы. Один из вопросов, требующих особого внимания, - плюрализм, как внутригрупповой, так и в контексте участия меньшинств в жизни общества в целом. Важно, чтобы плюрализм учитывал в том числе (но не только) гендерные вопросы. Не ограничиваясь общей нормой свободы ассоциаций, следует на инклюзивной основе организовать обсуждение конкретных вопросов политики, которую государства-участники ОБСЕ могли бы проводить с целью обеспечить плюрализм меньшинств, а также вопроса о том, как Лундские рекомендации могут помочь расширить наше понимание данной концепции (включая ее последствия) и оценить ее влияние на политику государств.

4. Самоуправление. Хотя с момента принятия в 1999 г. Лундских рекомендаций в географическом регионе ОБСЕ не возникло ни одно новое автономное территориальное образование, а в международном праве не появилась (и вряд ли появится) норма, закрепляющая право на автономию, различные аспекты самоуправления неизбежно останутся в центре внимания ВКНМ и ОБСЕ, особенно в контексте трансграничных регионов ОБСЕ. Как показывает пример венгерского меньшинства в Украине, комплексная взаимосвязь между требованиями самоуправления, интеграцией и десекьюритизацией нуждается в надлежащей про- 
работке и формулировании соответствующих выводов, если мы хотим, чтобы Лундские рекомендации были востребованы в таких ситуациях (в сочетании с Люблянскими рекомендациями по интеграции и Больцанскими рекомендациями о национальных меньшинствах в межгосударственных отношениях). Целостный подход к решению вопросов самоуправления, сформулированный в виде стандартов ВКНМ, должен обеспечить более последовательный синтез этих вопросов и на этой основе - подготовку конкретных рекомендаций для отдельных стран.

Следуя устоявшейся схеме работы, Верховный комиссар мог бы созывать и спонсировать встречи экспертов с целью инициировать официальный пересмотр и доработку Лундских рекомендаций на перечисленных выше направлениях, подготовить консолидированную версию рекомендаций ВКНМ, провести серию целенаправленных последующих мероприятий. В настоящей работе мы не преследовали цель оценить плюсы и минусы тех или иных вариантов решения рассмотренных проблем, а попытались определить ключевые вопросы участия меньшинств в общественно-политической жизни, в которых предлагаемая ВКНМ дружественная консультативная помощь должна содействовать нахождению баланса между стратегиями интеграции и сепарации. Независимо от того, какой путь будет выбран, очевидно, что любая подобная инициатива должна опираться на активное участие и поддержку государств-участников ОБСЕ, являющиеся необходимым условием для продуктивной деятельности ВКНМ.

\section{Примечания}

1 О мандате ВКНМ и дополнительные ресурсы см.: Mandate. OSCE High Commissioner on National Minorities // Официальный сайт ОБСЕ. URL: https://www.osce.org/hcnm/10787 8. См. также: Packer J. Making International Law Matter in Preventing Ethnic Conflict: A Practitioner's Perspective // New York University Journal of International Law and Politics. 2000. No. 3. P. 715-724.

2 Практически все Верховные комиссары придерживались этого подхода на протяжении последних почти тридцати лет. См., к примеру: Speech by Max van der Stoel, High Commissioner on National Minorities, at a Seminar, Prague // Официальный сайт ОБСЕ. 1994. 13 May. URL: http://www.osce.org/hcnm/37259; Early Warning and Early Action: Preventing Inter-Ethnic Conflict. Speech by Max van der Stoel, OSCE High Commissioner on National Minorities, at the Royal Institute of International Affairs. London, 9 July 1999 // Официальный сайт ОБСЕ. URL: https://www.osce.org/files/f/documents/6/5/32107.pdf; Keynote Speech by Lamberto Zannier, OSCE High Commissioner on National Minorities, to the United Nations Forum on Minority Issues. Geneva, Switzerland, 27 November 2019 // Официальный сайт ОБСЕ. URL: https://www.osce.org/files/f/documents/b/c/440084_0.pdf.

3 Особенно активно этот подход отстаивал Л. Заньер. См., в частности: Кеynote Speech by Lamberto Zannier, OSCE High Commissioner on National Minorities, to the United Nations 
Forum on Minority Issues. Более широкий анализ см. также: Language Policy and Conflict Prevention / I. Ulasiuk., L. Hadîrcă, W. Romans (eds). - Leiden; Boston: Brill/Nijhoff, 2018.

См., в частности: ЮНЕСКО: Конвенция о борьбе с дискриминацией в области образования // Официальный сайт OOH. URL: https://www.un.org/ru/documents/decl_conv/convention s/educat.shtml; Документ Копенгагенского совещания Конференции по человеческому измерению СБСЕ. § 34 // Официальный сайт ОБСЕ. URL: https://www.osce.org/files/f/docume $\mathrm{nts} / \mathrm{d} / 0 / 14305 . \mathrm{pdf}$; Совет Европы: Рамочная конвенция о защите национальных меньшинств. Ст. 14(3) // Официальный сайт Совета Европы. URL: https://rm.coe.int/168007cddc. См. также: Pentassuglia G. Minorities in International Law. - Strasbourg: Council of Europe Publishing; ECMI, 2002.

5 Лундские рекомендации об эффективном участии национальных меньшинств в общественно-политической жизни с пояснительными примечаниями. Сентябрь 1999 года // Официальный сайт ОБСЕ. URL: https://www.osce.org/files/f/documents/2/b/32252.pdf.

6 Political Participation of Minorities: A Commentary on International Standards and Practice / M.Weller (ed). - Oxford: Oxford University Press, 2010. См. также: Suksi M. Effective Participation of Minorities in Public Affairs and Public Life: European Norms and Praxis Evaluated in Light of the Lund Recommendations // Beyond International Conditionality: Local Variations of Minority Representation in Central and South-Eastern Europe / V. Balázs, T. Norbert, E. Dobos,. - Baden-Baden: Nomos, 2017. P. 11-49; Language Policy and Conflict Prevention.

7 Commentary on the Effective Participation of Persons Belonging to National Minorities in Cultural, Social and Economic Life and in Public Affairs. Advisory Committee on the Framework Convention for the Protection of National Minorities, ACFC/31DOC(2008)001, 27 February 2008 // Официальный сайт Совета Европы. URL: https://rm.coe.int/CoERMPublicC ommonSearchServices/DisplayDCTMContent?documentId=09000016800bc7e8.

8 Международный пакт о гражданских и политических правах, 16 декабря 1966 // Официальный сайт OOH. URL: https://www.un.org/ru/documents/decl_conv/conventions/pactpol.sht $\mathrm{ml}$.

9 Лундские рекомендации об эффективном участии национальных меньшинств в общественно-политической жизни. С. 27.

10 Commentary on the Effective Participation of Persons Belonging to National Minorities in Cultural, Social and Economic Life and in Public Affairs. § 78.

11 См.: Рекомендации, способствующие участию национальных меньшинств в избирательном процессе, 1 января 2001. Бюро ОБСЕ по демократическим институтам и правам человека // Официальный сайт ОБСЕ. URL: https://www.osce.org/files/f/documents/c/0/1757 1.pdf. См. также: Code of good practice in electoral matters. Guidelines and explanatory report. October 2002 // European Commission for Democracy through law (Venice Commission). URL: https://www.venice.coe.int/webforms/documents/?pdf=CDL-AD(2002)023rev2-cor-e.

12 Commentary on the Effective Participation of Persons Belonging to National Minorities in Cultural, Social and Economic Life and in Public Affairs. § 78.

13 См.: Nurumov D., Vashchanka V. Effective Participation of National Minorities in the Electoral Process // Language Policy and Conflict Prevention. P. 197-211.

14 Лундские рекомендации об эффективном участии национальных меньшинств в общественно-политической жизни. С. 25-28.

15 Старший юридический советник ВКНМ в то время отметил, что с точки зрения Верховного комиссара данное соглашение «казалось полезным средством обеспечения эффективного участия меньшинств и их интеграции». См.: Drzewicki K. OSCE Lund Recommendations in the Practice of the High Commissioner on National Minorities // Political Participation of Minorities: A Commentary on International Standards and Practice. P. 274. 
16 Комитет по ликвидации расовой дискриминации. Семьдесят пятая сессия, 3-28 августа 2009 года. Общая рекомендация XXXII. Значение и сфера применения особых мер в Международной Конвенции о ликвидации всех форм расовой дискриминации. Документ CERD/C/GC/32 // Официальный сайт OOH. URL: https://undocs.org/pdf?symbol=ru/CERD/C $/ \mathrm{GC} / 32$.

17 Можно утверждать, что этот вывод прямо или косвенно подтверждается положениями Рамочной конвенции Совета Европы и практикой Европейского суда по правам человека. См.: Suksi M. Op. cit. P. 31, 33-34.

18 См.: Language Policy and Conflict Prevention / I. Ulasiuk., L. Hadîrcă, W. Romans (eds). Leiden; Boston: Brill/Nijhoff, 2018. P. 210-211.

19 Лундские рекомендации об эффективном участии национальных меньшинств в общественно-политической жизни. С. 12.

20 Cм.: Grosaru v. Romania, Appl. No. 78039/01, European Court of Human Rights, Judgment of 2 March 2010; Ofensiva Tinerilor v. Romania, Appl. No. 16732/05, European Court of Human Rights, Judgment of 15 December 2015.

21 Pentassuglia G. Minority Groups and Judicial Discourse in International Law. - Leiden and Boston: Brill/Nijhoff, 2009. P. 142-147.

22 Petrenko Thomsen A. Taking the Lund Recommendations One Step Forward: Introducing a Measurement Approach // Language Policy and Conflict Prevention. P. 230-252.

23 Лундские рекомендации об эффективном участии национальных меньшинств в общественно-политической жизни. С. 13-15.

24 Address by Lamberto Zannier, OSCE High Commissioner on National Minorities, to the 1270th Plenary Meeting of the OSCE Permanent Council. Vienna, Austria - 4 June 2020. Document HCNM.GAL/3/20/Rev.2. P. 3 // Официальный сайт ОБCE. URL: https://www.osce.org/files/f/ documents/1/1/453807.pdf.

25 Люблянские рекомендации по интеграции разнообразных обществ, ноябрь 2012 // Официальный сайт ОБСE. URL: https://www.osce.org/files/f/documents/2/a/111071.pdf; Больцанские рекомендации о национальных меньшинствах в межгосударственных отношениях и пояснительная записка. 20 июня 2008 // Официальный сайт ОБCE. URL: https://www.osce.o rg/files/f/documents/6/9/33634.pdf.

26 Люблянские рекомендации по интеграции разнообразных обществ. С. 19.

27 Smith D., Semenyshyn M. Addressing Hungarian Minority Self-Governance Claims in Zakarpattya: An Assessment in Light of the Lund Recommendations // Language Policy and Conflict Prevention. P. 123-143.

28 Address by Kairat Abdrakhmanov, OSCE High Commissioner on National Minorities, to the 1318th Plenary meeting of the OSCE Permanent Council. Vienna, Austria - 3 June 2021. Document HCNM.GAL/3/21/Rev.1. P. 10-11 // Официальный сайт ОБСE. URL: https://www. osce.org/files/f/documents/a/4/489767_0.pdf. 
